\title{
At-Taqaddum
}

Vol. 10 No. 2 (2018) pp 201-218

DOI: http://dx.doi.org/10.21580/at.v10i2.3028

\section{ANALISIS PENGARUH AKREDITASI PROGRAM STUDI TERHADAP INTENSITAS BELAJAR DAN HARAPAN MASA DEPAN \\ (Studi Kasus di Fakultas Sains dan Teknologi UIN Walisongo Semarang)}

\author{
Eva Khoirun Nisa \\ Universitas Islam Negeri Walisongo Semarang \\ Email: evakn@walisongo.ac.id
}

\begin{abstract}
The quality of a study program is assessed from the results of accreditation. Accreditation is also one of the requirements in applying for a job in a public or private institution. The hope is that the results of university accreditation will be satisfactory when students graduate from the college. With the Friedman test statistic, it can be seen the effect of the study program accreditation in the Faculty of Science and Technology on the learning intensity and future expectations in this study. It turned out that descriptively, the A study program's accreditation motivated students to study diligently and students really hoped to get a job or reputable college for further studies. In contrast, the students from study programs are accredited $B$, and $C$ have medium and low learning intensity. Their hopes of getting a good job or place of further study are almost ordinary or almost nonexistent.
\end{abstract}

Keywords: Study program accreditation, learning intensity, future expectation, Friedman test

\begin{abstract}
Abstrak
Kelayakan mutu suatu program studi (prodi) dinilai dari hasil akreditasi. Akreditasi juga menjadi salah satu syarat dalam melamar pekerjaan di suatu institusi baik negeri maupun swasta. Harapannya hasil akreditasi perguruan tinggi memuaskan ketika mahasiswa lulus dari perguruan tinggi tersebut. Dengan statistik uji Friedman, dapat diketahui adanya pengaruh perguruan tinggi untuk studi lanjut
\end{abstract}

Eva Khoirun Nisa, Analisis Pengaruh Akreditasi ... 
bereputasi baik. Sebaliknya mahasiswa dari prodi berakreditasi B, dan $\mathrm{C}$ mempunyai intensitas belajar yang sedang dan rendah. Harapan mereka untuk memperoleh pekerjaan atau tempat studi lanjut yang baik pun hampir biasa saja atau bahkan hampir tidak ada.

Keywords: Akreditasi prodi, intensitas belajar, harapan masa depan, uji Friedman

\section{Pendahuluan}

Akreditasi merupakan suatu penilaian kualitas terhadap sebuah institusi termasuk perguruan tinggi. Menurut Permenristekdikti No. 32 Tahun 2016, akreditasi adalah kegiatan penilaian untuk menentukan kelayakan Program Studi dan Perguruan Tinggi ${ }^{1}$. Selain kelayakan mutu suatu program studi (prodi) dan perguruan tinggi (PT), alasan penting akreditasi prodi dan perguruan tinggi lainnya adalah akreditasi menjadi salah satu syarat dalam melamar pekerjaan di suatu institusi baik negeri maupun swasta. Terlebih penerimaan CPNS sudah lama mensyaratkan hasil akreditasi baik akreditasi program studi maupun perguruan tinggi saat mahasiswa lulus. Begitu pula akreditasi menjadi salah satu pertimbangan calon mahasiswa dalam memilih tempat kuliah mereka.

Fakultas Sains dan Teknologi merupakan salah satu fakultas baru yang ada di UIN Walisongo Semarang. Fakultas yang lahir pada tanggal 4 Nopember 2015 ini mempunyai delapan program studi (prodi) ${ }^{2}$ dengan satu akreditasi A, tiga akreditasi B dan empat akreditasi C. Prodi dengan akreditasi C merupakan prodi baru yang lahir pada tahun 2015 dan pada tahun 2017 mengajukan akreditasi dengan hasil akreditasi C. Ke-empat

\footnotetext{
${ }^{1}$ Permenristekdikti No. 32 Tahun 2016

${ }^{2}$ Fakultas Sains dan Teknologi, Pedoman Akademik Fakultas Sains dan Teknologi (Semarang: Fakultas Sains dan Teknologi, 2015)
} 
prodi berakreditasi C yaitu Matematika, Fisika, Biologi, dan Kimia ${ }^{3}$. Hasil akreditasi ini melahirkan kekecewaan pada pihak prodi terlebih mahasiswa ke-empat prodi tersebut. Mereka secara langsung menanggung dampaknya ketika akreditasi prodi mereka tidak baik.

Selama ini masih sedikit penelitian yang membahas secara langsung pengaruh hasil akreditasi prodi terhadap motivasi belajar mahasiswa. Menurut Joe B, performance mahasiswa dalam hal ini motivasi semangat belajar dipengaruhi oleh jarak kampus dengan tempat tinggal, jenis kelamin, usia ${ }^{4}$. Ketiga faktor tersebut merupakan faktor dari dalam mahasiswa. Berbeda dengan Joe B., Yveonne mengungkapkan bahwa performance akademik mahasiswa sangat dipengaruhi oleh latar belakang sosial ekonomi mahasiswa ${ }^{5}$. Semakin tinggi status ekonomi keluarga mahasiswa maka semakin mudah dia memperoleh fasilitas pendukung pembelajaran sehingga semakin meningkat performance akademiknya.

Hendrawan meneliti dampak kebijakan akreditasi terhadap daya saing perguruan tinggi swasta di Kebumen ${ }^{6}$. Sesuai teori adanya kebijakan akreditasi mengharuskan perguruan tinggi baik negeri maupun swasta berupaya meningkatkan mutu pendidikan di institusinya agar dapat bersaing dengan perguruan tinggi di sekitarnya. Namun, hasil riset yang

\footnotetext{
${ }^{3}$ SK BAN-PT No. 5128/SK/BAN-PT/Akred/S/XII/2017

${ }^{4}$ Joe B Hansen, "Student Performance and Student Growth as Measure of Success: A Evaluator's Perspective," Paper presented at annual meeting American Educational Research Association (Lousiana 2000).

5 Yvonne B, "An Analysis of High School Students' Performance on Five Integrated Science Process Skills," Research in Science \& Technical Education Vol. 19 No.2 (1998):133-145.

${ }^{6}$ Hendrawan P., "Dampak Kebijakan Akreditasi Perguruan Tinggi Terhadap daya Saing (Competitiveness) Perguruan Tinggi Swasta di Kabupaten Kebumen," Jurnal Fokus Bisnis Vo. 13 No.01 (2014): 1-12.
} 
dia lakukan menyatakan bahwa tidak adanya daya saing antar perguruan tinggi swasta di Kebumen karena dari lima perguruan tinggi swasta yang ada di Kebumen hanya dua yang sudah mempunyai lembaga penjamin mutu internal. Ini menyebabkan hanya dua perguruan tinggi tersebut yang berusaha meningkatkan mutu dan mempunyai daya saing dalam penerimaan mahasiswa baru maupun dalam memperoleh dana bantuan penelitian.

Hamzah B. Uno menyebutkan terdapat enam indikator motivasi belajar yaitu ${ }^{7}$

1) Adanya hasrat dan keinginan berhasil

2) Adanya dorongan dan kebutuhan dalam belajar

3) Adanya harapan atau cita-cita masa depan

4) Adanya penghargaan dalam belajar

5) Adanya kegiatan yang menarik dalam belajar

6) Adanya lingkungan belajar yang kondusif, sehingga memungkinkan seorang siswa dapat belajar

dengan baik.

Lain halnya Hamzah, Sugihartono dkk menyatakan ciri siswa yang mempunyai motivasi belajar adalah adanya kualitas keterlibatan mahasiswa dalam belajar yang tinggi, adanya perasaan dan keterlibatan afektif siswa yang tinggi dalam belajar, serta adanya upaya upaya siswa untuk senantiasa memelihara atau menjaga agar memiliki motivasi belajar yang tinggi ${ }^{8}$. Keterlibatan mahasiswa dalam belajar atau intensitas belajar

\footnotetext{
${ }^{7}$ Hamzah B. Uno. Teori Motivasi dan Pengukurannya (Jakarta: Bumi Aksara, 2008).

${ }^{8}$ Sugihartono, dkk. Psikologi Pendidikan (Yogyakarta: UNY Press, 2007).
} 
menjadi salah satu indikator utama pada motivasi belajar selain adanya harapan atau cita-cita masa depan. Oleh karena itu, dua indikator belajar tersebut yaitu intensitas belajar (keterlibatan mahasiswa dalam belajar) dan adanya harapan atau cita-cita masa depan menjadi variabel yang digunakan pada penelitian ini.

Motivasi belajar mahasiswa diduga dipengaruhi oleh hasil akreditasi prodi. Pada tanggal 13-16 Maret 2018 dilakukan interview pada 10 mahasiswa prodi Matematika mengenai respon mereka terhadap hasil akreditasi prodi mereka yang baru keluar. Dari hasil interview tersebut ternyata delapan mahasiswa sengaja mengulur mengajukan judul skripsi sampai ada hasil akreditasi terbaru dari reakreditasi prodi. Mereka juga mengalami kebimbangan dalam menentukan kapan mereka akan lulus sementara hasil akreditasi prodi masih C. Melihat kondisi ini maka dibutuhkan analisis untuk mengetahui apakah terdapat perbedaan intensitas belajar dan adanya harapan masa depan mahasiswa berdasarkan hasil akreditasi prodinya A, B, dan C. Dengan kata lain apakah ada pengaruh hasil akreditasi prodi terhadap intensitas belajar dan adanya harapan masa depan mahasiswa.

Ketika dihadapkan pada lebih dari dua sampel dengan variabel kategori berskala nominal atau ordinal maka analisis statistika yang tepat diterapkan adalah uji Friedman. Uji Friedman merupakan salah satu metode statistika nonparametrik dengan $k$ sampel berhubungan ${ }^{9}$. Dengan pengujian ini tepatlah sampel yang digunakan yaitu tiga kelompok sampel yang terdiri dari mahasiswa dari prodi berakreditasi A, B, dan C. Dari

\footnotetext{
${ }^{9}$ Kraska, M., \& Miller. Nomparametric Statistics for Social and Behavioral Sciences (New York: CRC Press, 2014).
} 
analisis Friedman dan ini akan diperoleh apakah memang ada pengaruh hasil akreditasi prodi intensitas belajar, adanya harapan masa depan. Selain itu, dengan ditambahi analisis statistika deskriptif akan teridentifikasi bagaimana intensitas belajar dan harapan akan masa depan mahasiswa dari masing-masing akreditasi prodi yang ada di Fakultas Sains dan Teknologi UIN Walisongo Semarang. Oleh karena itu, pentingnya penelitian ini dilaksanakan dengan harapan dapat membantu pihak prodi, fakultas dan universitas dalam meningkatkan mutu pendidikan sehingga diperoleh akreditasi yang terbaik.

\section{Akreditasi}

Secara terminologi akreditasi didefinisikan sebagai suatu proses penilaian kualitas dengan menggunakan kriteria baku mutu yang di tetapkan dan bersifat terbuka ${ }^{10}$ sedangkan Permenristekdikti Nomor 32 Tahun 2016 tentang Akreditasi Program Studi dan Perguruan Tinggi menyebutkan akreditasi adalah kegiatan penilaian untuk menentukan kelayakan Program Studi dan Perguruan Tinggi. Seperti halnya masyarakat umum menilai kualitas program studi (prodi) atau perguruan tinggi (PT) dari hasil akreditasinya. Akreditasi Program Studi dan Perguruan Tinggi dibedakan menjadi empat yaitu tidak terakreditasi, terakreditasi cukup (C), terakreditasi baik (B), dan terakreditasi sangat baik (A).

${ }^{10}$ Mulyo. Manajemen Administrasi dan Organisasi Pendidikan (Yogyakarta : Ar-Ruzz Media, 2008). 
Sukardi mengatakan bahwa akreditasi perguruan tinggi/lembaga/madrasah atau lembaga lain secara garis besar mempunyai variasi tujuan penting, diantaranya ${ }^{11}$ :

1. Memberikan informasi kepada masyarakat tentang tingkat kelayakan baik suatu layanan maupun kinerja suatu lembaga dalam menyelenggarakan layanan pendidikan,

2. Menjadi acuan bagi pemerintah dalam memberikan bantuan

3. Menjadi acuan bagi masyarakat dalam memilih dan mempercayakan anaknya untuk lembaga di lembaga tersebut

4. Sebagai bentuk akuntabilitas penyelenggara lembaga tentang gambaran kinerja lembaga sebagai bentuk pertanggung jawaban lembaga terhadap apa yang telah dilakukan sebagai pengelola.

Dengan demikian, pentingnya akreditasi bagi mahasiswa terlebih bagi lulusan. Lulusan dari perguruan tinggi berakreditasi A tentunya dianggap mahasiswa yang mempunyai kompetensi tinggi karena PT asalnya sudah layak baik dalam kualitas pendidikan. Selanjutnya akan dipercaya oleh para pembuka lapangan kerja bahwa dia pantas menempati posisi pekerjaan yang ditawarkannya.

\section{Intensitas Belajar}

Kata intensitas berasal dari bahasa Inggris yaitu intense yang berarti semangat, giat. Menurut Kamus Besar Bahasa Indonesia ${ }^{12}$, intensitas diartikan sebagai keadaan tingkatan atau ukuran intensnya. Intensitas

\footnotetext{
${ }^{11}$ Sukardi. Evaluasi Program Pendidikan dan Kepelatihan (Jakarta: Bumi Aksara, 2014)

${ }^{12}$ Tim Penyusun. Kamus Besar Bahasa Indonesia (Jakarta: Pusat Bahasa, 2008)
} 
belajar adalah seberapa sering usaha siswa yang dapat menghasilkan perubahan- perubahan dalam pengetahuan, pemahaman, keterampilan nilai dan sikap. Sardiman mengemukakan intensitas belajar siswa sangat menentukan tingkat pencapaian tujuan belajarnya yakni tingkatan hasil belajarnya $^{13}$. Dengan demikian, siswa dapat memperoleh beberapa kemudahan dalam belajar, seperti dapat mengatur waktu belajar, membangkitkan motivasi, dan lebih mudah mengingat materi pembelajaran karena apabila ada beban belajar yang lebih besar ia dapat mempersiapkan diri karena ia belajar dengan rutin. Pada penelitian ini intensitas belajar dikategorikan menjadi tiga yaitu kurang dari dua jam, 24 jam, dan lebih dari empat jam setiap harinya.

\section{Harapan Masa Depan}

Harapan didefinisikan sebagai kemampuan untuk merencanakan jalan keluar dalam upaya mencapai tujuan walaupun adanya rintangan dan menjadikannya motivasi sebagai suatu cara dalam mencapai tujuan ${ }^{14}$. Di dalam Kamus Besar Bahasa Indonesia, harapan adalah keinginan supaya menjadi kenyataan sedangkan cita-cita merupakan keinginan (kehendak) yang selalu ada di dalam pikiran ${ }^{15}$. Jadi secara garis besar harapan atau cita-cita merupakan keinginan yang selalu diupayakan agar tercapai. Trommsdorf dalam Nurmi menyatakan orientasi masa depan merupakan

\footnotetext{
${ }^{13}$ Sardiman. Interaksi dan Motivasi Belajar Mengajar (Jakarta: Rajawali Press, 2011)

14 Alan Carr. Positive Psychology, The Science of Happiness and Human Strength (New York: Brunner-Routledge, 2004)

15 Tim Penyusun. Kamus Besar Bahasa Indonesia (Jakarta: Pusat Bahasa, 2008)
} 
fenomena kognitif, motivasional yang kompleks yaitu antisipasi dan evaluasi future self dalam interaksinya dengan lingkungan. ${ }^{16}$

Harapan atau cita-cita dari mahasiswa ketika dia lulus dari perguruan tinggi tentunya memperoleh pekerjaan yang baik dalam waktu tidak lama. Selain dari kompetensi diri mahasiswa juga faktor kualitas perguruan tinggi ketika dia lulus juga menjadi pertimbangan perusahaan atau instansi yang membuka lowongan kerja. Akreditasi menjadi salah satu tolok ukur kualitas dari perguruan tinggi atau program studi. Sudah banyak instansi pemerintahan atau perusahaan mensyaratkan akreditasi prodi dalam menerima tenaga kerja. Penerimaan CPNS yang menjadi incaran setiap pencari kerja sudah mensyaratkan akreditasi prodi dan perguruan tinggi minimal B sesuai Peraturan Pemerintah No.11 Tahun 2017. Terlebih di dalam penerimaan CPNS terdapat formasi cumlaude untuk lulusan dengan IPK cumlaude dan akreditasi perguruan tinggi serta prodi pendidikan terakhirnya A. Dengan demikian, ada kemungkinan hasil akreditasi prodi berpengaruh pada harapan atau cita-cita masa depan. Untuk penelitian ini, harapan masa depan dikategorikan menjadi tiga yaitu hampir tidak berharap, berharap biasa saja (sewajarnya), dan sangat berharap.

\section{Pengujian Instrumen}

Untuk mengetahui apakah instrumen yang digunakan dalam penelitian ini menjalankan fungsi ukurnya atau tidak maka terlebih dahulu diuji validitas dan reliabilitas agar instrumen pertanyaan valid dan reliable.

${ }^{16}$ J-E Nurmi. "Planning, Motivation And Evaluation In Orientation To The Future: A Latent Structure Analysis," Scandinavian Journal of Psychology. Vol. 30 (1989): 64-71. 
Pengujian validitas disini menggunakan korelasi product moment dengan statistik uji sebagai berikut ${ }^{17}$.

$$
r_{x y}=\frac{N \sum X Y-\left(\sum X\right)\left(\sum Y\right)}{\sqrt{\left\{N \sum X^{2}-\left(\sum X\right)^{2}\right\}\left\{N \sum Y^{2}-\left(\sum Y\right)^{2}\right\}}}
$$

Keterangan:

$$
\begin{array}{ll}
\mathrm{r}_{\mathrm{xy}} & =\text { Koefisien korelasi antara variabel } \mathrm{x} \text { dan } \mathrm{y} \\
\mathrm{N} & =\text { Banyaknya peserta tes } \\
\Sigma \mathrm{x} & =\text { Jumlah skor item } \\
\Sigma \mathrm{Y} & =\text { Jumlah skor total item } \\
\Sigma \mathrm{XY} & =\text { Hasil perkalian anatara skor item dan skor total }
\end{array}
$$

Kemudian hasil $r_{x y}\left(\mathrm{r}_{\text {hitung }}\right)$ yang diperoleh dari perhitungan dibandingkan dengan harga $r_{\text {tabel. }}$ Uji validitas diukur melalui kriteria:
a. Jika $\mathrm{r}_{\text {hitung }}>\mathrm{r}_{\text {tabel }}$ maka butir soal tersebut dinyatakan valid.
b. Jika $\mathrm{r}_{\text {hitung }}<\mathrm{r}_{\text {tabel }}$ maka butir soal tersebut dinyatakan tidak valid.

Adapun statistik uji yang digunakan untuk menguji reliabilitas yaitu Alpha Cronbach seperti tertulis di bawah ini ${ }^{18}$.

$$
r_{11}=\left(\frac{n}{n-1}\right)\left(1-\frac{\sum s_{i}^{2}}{S_{i}^{2}}\right)
$$

${ }_{17}$ Suharsimi Arikunto. Manajemen Penelitian (Jakarta: Rineka Cipta, 2005)

${ }^{18}$ Ibid 


\section{Keterangan :}

$r_{11} \quad:$ Reliabilitas tes secara keseluruhan

n : Banyak item pertamyaan

$\sum S_{i}{ }^{2} \quad: \quad$ Jumlah varians skor dari tiap - tiap butir

pertanyaan

$$
S_{i}^{2} \quad: \text { Varians total }
$$

Instrumen pertanyaan dikatakan reliabel jika nilai $r_{11}>r_{\text {tabel. }}$.

\section{Sampel dan Teknik Penarikan Sampel}

Populasi pada penelitian ini adalah mahasiswa semester VI Fakultas Sains dan Teknologi (FST) UIN Walisongo Semarang yang terdiri dari mahasiswa program studi (prodi) Matematika, Fisika, Kimia, Biologi, Pendidikan Matematika, Pendidikan Fisika, Pendidikan Kimia, dan Pendidikan Biologi. Untuk besaran sampel ditentukan dengan rumus Slovin, yaitu ${ }^{19}$

$$
n=\frac{N}{1+N e^{2}}
$$

dimana:

$\mathrm{n}=$ ukuran sampel

$\mathrm{N}=$ ukuran populasi

$\mathrm{e}=$ persen toleransi ketidaktelitian karena kesalahan

pengambilan sampel yang masih dapat ditolerir atau diinginkan

Teknik sampling yang digunakan adalah proportionate stratified random sampling. Menurut Sugiyono, proportionate stratified random sampling

19 Budi Koestoro dan Basrowi. Metodologi Penelitian Kualitatif (Kediri:Jenggala Pustaka Utama, 2006) 
adalah teknik yang digunakan bila populasi mempunyai anggota/unsur yang tidak homogen dan berstrata secara proporsional ${ }^{20}$. Untuk menentukan besarnya sampel pada setiap kelas dilakukan dengan alokasi proporsional agar sampel yang diambil lebih proporsional yaitu

$$
\text { Jumlah sampel tiap kelas } \quad=\frac{\text { jumlah tiap kelas }}{\text { jumlah populasi }} \times \text { jumlah sampel }
$$

\section{Uji Friedman}

Salah satu metode statistika nonparametrik yang dapat menguji perbedaan lebih dari dua sampel saling berhubungan adalah pengujian Friedman. Pengujian Friedman merupakan uji analisis varian berdasarkan perankingan yang bertujuan untuk mengevaluasi perbedaan median diantara tiga atau lebih observasi. Hipotesis nol dalam pengujian ini tidak ada perbedaan signifikan median antar observasi sedangkan hipotesis alternatif menyatakan ada perbedaan signifikan median antar observasi ${ }^{21}$. Statistik uji yang digunakan merupakan pendekatan dari Chi Square yaitu ${ }^{22}$

$$
\chi^{2}=\frac{12 \sum\left(\sum R_{T}\right)^{2}}{n k(k+1)}-3 n(k+1)
$$

dengan

$$
\begin{aligned}
\sum R_{T} & =\text { jumlah ranking tiap sampel } \\
\mathrm{n} & =\text { jumlah data tiap sampel } \\
\mathrm{k} & =\text { banyaknya sampel }
\end{aligned}
$$

\footnotetext{
${ }^{20}$ Sugiyono. Metode Penelitian Kuantitatif, Kualitatif, dan R\&D (Bandung: Alfabeta, 2010)

${ }^{21}$ Kraska, M., \& Miller. Nomparametric Statistics for Social and Behavioral Sciences (New York: CRC Press, 2014)

22 Ibid
} 
$\mathrm{H}_{0}$ ditolak ketika $\chi_{\text {hitung }}^{2}>\chi_{\alpha, k-1}^{2}$ atau $\mathrm{p}$-value $<\alpha$

\section{Hasil dan Pembahasan}

Berikut adalah hasil pengujian validitas instrumen yang digunakan dalam penelitian ini.

Tabel 1 Hasil Pengujian Validitas Instrumen

\begin{tabular}{cccc}
\hline Pertanyaan & $\mathbf{r}_{\text {hitung }}$ & $\mathbf{r}_{\text {tabel }}$ & Kriteria \\
\hline 1 & 0,733 & 0,361 & Valid \\
\hline 2 & 0,467 & 0,361 & Valid \\
\hline 3 & 0,641 & 0,361 & Valid \\
\hline 4 & 0,805 & 0,361 & Valid \\
\hline 5 & 0,510 & 0,361 & Valid \\
\hline 6 & 0,626 & 0,361 & Valid \\
\hline
\end{tabular}

Berdasarkan tabel di atas semua instrumen pertanyaan valid. Selain validitas, reliabilitas untuk instrumen yang digunakan juga terpenuhi karena nilai statistik uji Alpha Cronbach 0,704 lebih besar dari 0,7. Dengan rumus Slovin, sampel yang terpilih sebanyak 195 mahasiswa dengan rincian perhitungan sebagai berikut.

1.Prodi Matematika: $\frac{24}{379} \times 195=12,64 \approx 13$

2.Prodi Pendidikan Matematika: $\frac{83}{379} \times 195=42,7 \approx 43$

3.Prodi Fisika: $\frac{27}{379} \times 195=13,89 \approx 14$

4.Prodi Pendidikan Fisika: $\frac{68}{379} \times 195=34,9 \approx 35$

5.Prodi Kimia: $\frac{25}{379} \times 195=12,34 \approx 12$ 
6.Prodi Pendidikan Kimia: $\frac{60}{379} \times 195=30,87 \approx 31$

7.Prodi Biologi: $\frac{25}{379} \times 195=12,86 \approx 13$

8.Prodi Pendidikan Biologi: $\frac{67}{379} \times 195=34,47 \approx 43$

Responden penelitian ini memiliki karakteristik hasil akreditasi sebagai berikut.

Tabel 2 Hasil Akreditasi Program Studi

\begin{tabular}{cccc}
\hline No & Nilai Akreditasi & Jumlah & Presentasi (\%) \\
\hline 1. & A & 34 & 17.4 \\
\hline 2. & B & 109 & 55.9 \\
\hline 3. & C & 52 & 26.7 \\
\hline & Total & 195 & 100 \\
\hline
\end{tabular}

Dari tabel di atas nilai akreditasi program studi dari responden yang paling banyak adalah B yakni 109 responden (55.9\%). Kemudian nilai C sebanyak 52 responden (26.7\%) dan yang paling sedikit nilai A 34 responden (17.4\%). Banyaknya responden yang berasal dari prodi berakreditasi B karena empat dari delapan program studi yang ada di FST merupakan prodi pendidikan yang sudah lama berdiri sedangkan jumlah responden terbesar selanjutnya merupakan mahasiswa dengan akreditasi prodi C. Sisanya berasal dari prodi Pendidikan Biologi dengan hasil kreditasi A.

Untuk mengetahui apakah terdapat perbedaan intensitas belajar dan harapan atau cita-cita masa depan mahasiswa antara mahasiswa dari prodi berakreditasi A, B, dan C maka digunakan Uji Friedman. Dengan 
bantuan SPSS, pengujian ini menghasilkan bahwa terdapat perbedaan intensitas belajar mahasiswa dari prodi berakreditasi A, B, dan C di Fakultas Sains dan Teknologi. Hal ini disebabkan $p-$ value $<\alpha(0,000<0,05)$. Begitu pula yang terjadi pada variabel tingkat harapan atau cita-cita masa depan mahasiswa ternyata terdapat perbedaan antara tingkat harapan mahasiswa dari prodi berakreditasi A, $\mathrm{B}$, dan $\mathrm{C}$ karena $p$-value $<\alpha(0,039<0,05)$ sehingga menolak $\mathrm{H}_{0}$. Dengan demikian, dapat disimpulkan bahwa hasil akreditasi prodi mempengaruhi intensitas belajar dan tingkat harapan atau cita-cita masa depan mahasiswa.

Langkah selanjutnya untuk mengetahui akreditasi manakah yang paling berpengaruh terhadap intensitas belajar dan tingkat harapan atau cita-cita masa depan mahasiswa, dapat kita lihat dari tabel kontingensi berikut.

Tabel 3 Tabel Kontingensi antara Akreditasi dengan Intensitas belajar

\begin{tabular}{|c|c|c|c|c|c|}
\hline & & \multicolumn{3}{|c|}{ Intensitas Belajar } & \multirow[b]{2}{*}{ Total } \\
\hline & & $\begin{array}{l}\text { kurang dari } \\
2 \text { jam }\end{array}$ & 2-4 jam & $\begin{array}{l}\text { lebih } \\
\text { dari } 4 \\
\text { jam }\end{array}$ & \\
\hline \multirow[t]{3}{*}{ Akreditasi } & $\mathrm{C}$ & 33 & 18 & 1 & 52 \\
\hline & $\mathrm{B}$ & 34 & 59 & 16 & 109 \\
\hline & A & 1 & 13 & 20 & 34 \\
\hline Total & & 68 & 90 & 37 & 195 \\
\hline
\end{tabular}

Dari Tabel 3 diperoleh informasi bahwa mahasiswa dengan akreditasi prodi A mempunyai intensitas belajar yang tinggi yaitu belajar labih dari empat jam per hari. Untuk yang dari prodi berakreditasi B 
sebanyak 50\% belajar 2-4 jam per hari sedangkan dari prodi berakreditasi C didominasi mahasiswa belajar kurang dari dua jam tiap harinya. Dapat diperoleh kesimpulan bahwa hasil akreditasi prodi berpengaruh pada motivasi belajar mahasiswa.

Tabel 4 Tabel Kontingensi antara Akreditasi dengan Tingkat Harapan

\begin{tabular}{|c|c|c|c|c|c|}
\hline & & \multicolumn{3}{|c|}{ Tingkat Harapan } & \multirow[b]{2}{*}{ Total } \\
\hline & & $\begin{array}{l}\text { Hampir } \\
\text { tidak } \\
\text { berharap }\end{array}$ & $\begin{array}{l}\text { Berharap } \\
\text { biasa saja }\end{array}$ & $\begin{array}{l}\text { Sangat } \\
\text { berharap }\end{array}$ & \\
\hline \multirow[t]{3}{*}{ Akreditasi } & $\mathrm{C}$ & 21 & 23 & 8 & 52 \\
\hline & $\mathrm{B}$ & 69 & 36 & 4 & 109 \\
\hline & $\mathrm{A}$ & 0 & 7 & 27 & 34 \\
\hline Total & & 90 & 66 & 39 & 195 \\
\hline
\end{tabular}

Berdasarkan Tabel 4 mahasiswa dari prodi berakreditasi A di Fakultas Sains dan Teknologi UIN Walisongo Semarang mempunyai harapan tinggi akan masa depannya. Tentunya hal ini sesuai teori yang ada bahwa mahasiswa akan mempunyai masa depan yang cerah ketika mereka lulus dengan hasil akreditasi prodinya sangat baik. Sebaliknya mahasiswa dari prodi berakreditasi B dan C mempunyai harapan yang biasa saja atau bahkan hampir tidak berharap memperoleh pekerjaan yang baik atau dapat melanjutkan studi lanjut karena mayoritas yang terjadi sekarang ini, perusahaan pencari kerja memilih lulusan dari prodi yang baik akreditasinya. Begitu pula perguruan tinggi yang mempunyai pascasarjana, akan menerima mahasiswa baru dari akreditasi prodi dan perguruan tinggi minimal B. Kebijakan tersebut sudah lama ditetapkan oleh perguruan tinggi di Indonesia terutama dari perguruan tinggi negeri. 


\section{Kesimpulan}

Hasil akreditasi prodi A, B, dan C berpengaruh secara signifikan pada intensitas belajar dan tingkat harapan atau cita-cita masa depan mahasiswa di Fakultas sains dan Teknologi UIN Walisongo Semarang. Kesimpulan ini diperoleh dari uji Friedman bahwa terdapat perbedaan intensitas belajar dan tingkat harapan atau cita-cita masa depan mahasiswa antara mahasiswa dari prodi berakreditasi A, B, dan C. Hasil akreditasi A memotivasi mahasiswanya untuk belajar dengan rajin sebaliknya mahasiswa dari prodi berakreditasi B, dan C mempunyai intensitas belajar yang sedang dan rendah. Harapan mereka untuk memperoleh pekerjaan atau tempat studi lanjut yang baik pun terpengaruh oleh hasil akreditasi prodi. Dengan demikian, harapannya dari pihak prodi segera mengajukan reakreditasi agar mahasiswa yang akan memasuki semester tujuh ini dapat lulus ketika hasil akreditasi prodi sudah berubah menjadi lebih baik

\section{Referensi}

Arikunto, Suharsimi. Manajemen Penelitian. Jakarta: Rineka Cipta, 2005.

Beaumont, Yvonne. “An Analysis of High School Students' Performance on Five Integrated Science Process Skills." Research in Science \& Technical Education Vol. 19, No.2 (1998):133-145.

Carr, Alan. Positive Psychology, The Science of Happiness and Human Strength. New York: Brunner-Routledge, 2004.

Fakultas Sains dan Teknologi. Pedoman Akademik Fakultas Sains dan Teknologi. Semarang: Fakultas Sains dan Teknologi UIN Walisongo, 2015. 
Hansen, Joe B. "Student Performance and Student Growth as Measure of Success: A Evaluator's Perspective." Paper presented at annual meeting American Educational Research Association (Lousiana, 2000)

Indarto, Wusono. “Analisis Karya Tulis (Skripsi) Tugas Akhir Mahasiswa Program Studi Administrasi Pendidikan Periode 2008/2009 dan 2009/2010." Jurnal EduChild Vol. 1, No.1 (2012)

Koestoro, Budi dan Basrowi. Metodologi Penelitian Kualitatif, Kediri:Jenggala Pustaka Utama, 2006.

Kraska, M., \& Miller. Nonparametric Statistics for Social and Behavioral Sciences. New York: CRC Press, 2014.

Mulyo. Manajemen Administrasi dan Organisasi Pendidikan. Yogyakarta:ArRuzz Media, 2008.

Nurmi, J-E. "Planning, Motivation And Evaluation In Orientation To The Future: A Latent Structure Analysis." Scandinavian Journal of Psychology Vol. 30 (1989): 64-71.

Peraturan Pemerintah No.11 Tahun 2017

Permenristekdikti Nomor 32 Tahun 2016

Prasetyo, Hendrawan. "Dampak Kebijakan Akreditasi Perguruan Tinggi Terhadap daya Saing (Competitiveness) Perguruan Tinggi Swasta di Kabupaten Kebumen." Jurnal Fokus Bisnis Vo. 13, No.01 (2014): 1-12.

Sardiman. Interaksi dan Motivasi Belajar Mengajar. Jakarta: Rajawali Press, 2011.

Sarwono, Jonathan. Statistik Multivariat Aplikasi Untuk Riset Skripsi. Yogyakarta: Andi Offset, 2013.

SK BAN-PT No. 5128/SK/BAN-PT/Akred/S/XII/2017

Sugihartono, dkk. Psikologi Pendidikan. Yogyakarta: UNY Press, 2007.

Sugiyono. Metode Penelitian Kuantitatif, Kualitatif, dan RéD. Bandung: Alfabeta, 2010.

Sukardi. Evaluasi Program Pendidikan dan Kepelatihan. Jakarta: Bumi Aksara, 2014.

Tim Penyusun. Kamus Besar Bahasa Indonesia. Jakarta: Pusat Bahasa, 2008. 